IZA DP No. 5469

Population Growth and Multiple Equilibria: Inferences from a Modified Ramsey Model

Ulla Lehmijoki

January 2011 


\title{
Population Growth and Multiple Equilibria: Inferences from a Modified Ramsey Model
}

\author{
Ulla Lehmijoki \\ University of Helsinki, \\ HECER and IZA
}

\author{
Discussion Paper No. 5469 \\ January 2011 \\ IZA \\ P.O. Box 7240 \\ 53072 Bonn \\ Germany \\ Phone: +49-228-3894-0 \\ Fax: +49-228-3894-180 \\ E-mail: iza@iza.org
}

Any opinions expressed here are those of the author(s) and not those of IZA. Research published in this series may include views on policy, but the institute itself takes no institutional policy positions.

The Institute for the Study of Labor (IZA) in Bonn is a local and virtual international research center and a place of communication between science, politics and business. IZA is an independent nonprofit organization supported by Deutsche Post Foundation. The center is associated with the University of Bonn and offers a stimulating research environment through its international network, workshops and conferences, data service, project support, research visits and doctoral program. IZA engages in (i) original and internationally competitive research in all fields of labor economics, (ii) development of policy concepts, and (iii) dissemination of research results and concepts to the interested public.

IZA Discussion Papers often represent preliminary work and are circulated to encourage discussion. Citation of such a paper should account for its provisional character. A revised version may be available directly from the author. 
IZA Discussion Paper No. 5469

January 2011

\section{ABSTRACT}

\section{Population Growth and Multiple Equilibria: Inferences from a Modified Ramsey Model}

The demographic transition is introduced into the otherwise standard Ramsey model to generate multiple equilibria, poverty traps, and demography-driven cycles. The model is calibrated for global data to explore the demographic conditions under which multiplicity is realized. Three cases arise, referring either to unique or multiple equilibria, and to transitional cycles. The calibrated model shows that multiple equilibria can explain a considerable fraction of the global income gap. The model provides a test to distinguish the trapped countries from those which just suffer from a long-lasting demographic recession, showing that the latter are more common than the former. Therefore, the economic effects of the demographic transition, even though considerable, are temporary rather than permanent.

JEL Classification: $\quad 041,011, \mathrm{~J} 11$

Keywords: demographic transition, optimal growth, multiple equilibria, poverty traps, calibrations

Corresponding author:

Ulla Lehmijoki

Department of Economics

P.O. Box 17 (Arkadiank. 7)

00014 University of Helsinki

Finland

E-mail: ulla.lehmijoki@helsinki.fi 


\section{Introduction}

This paper shows that the demographic transition in the otherwise standard Ramsey model can generate multiple equilibria, poverty traps, and demography-driven transitional cycles. While the idea that demography induces multiplicity is not new, we do not know the demographic conditions under which this multiplicity is realized or the extent to which the current global income gap can be explained by demographic poverty traps and demography-driven cycles. Neither can we tell whether a slow-growing country is trapped or just suffering from a long-lasting recession associated with these cycles.

In this paper, the demographic transition is introduced into the Ramsey model by assuming that the population growth rate is a function of income per head such that it initially rises and then slows down. This closed-form assumption in supported by several foundations in the literature. The child demand theory, for example, maintains that the assumed pattern follows from a switch of dominance from the income to the substitution effect (Becker, 1960). In particular, a rise in women's wages tends to generate this switch (Galor and Weil, 1996; Lagerlöf 2003) and it may also be due to a power shift in favor of women who usually want to have less children than men (Bergstrom, 2007). Galor and Weil (2000) claim that the substitution effect is further amplified by technical progress. Caldwell (1982), in turn, highlights the role of intergenerational wealth flows: if these flows run from children to parents, they have every reason to raise large families. Therefore, policies to limit child labor can generate a change in fertility trends (Hazan and Berdugo, 
2002; Doepke, 2004). The differential fertility hypothesis from de la Croix and Doepke (2003) maintains that the income distribution matters much as the poorer are more fertile than the richer. Since fertility and education are joint decisions, public schooling should generate a shift from high to low fertility (de la Croix and Doepke, 2004) and the effect should be the most visible in developing countries, where the fertility differentials are the most widespread (Kremer and Chen, 2002).
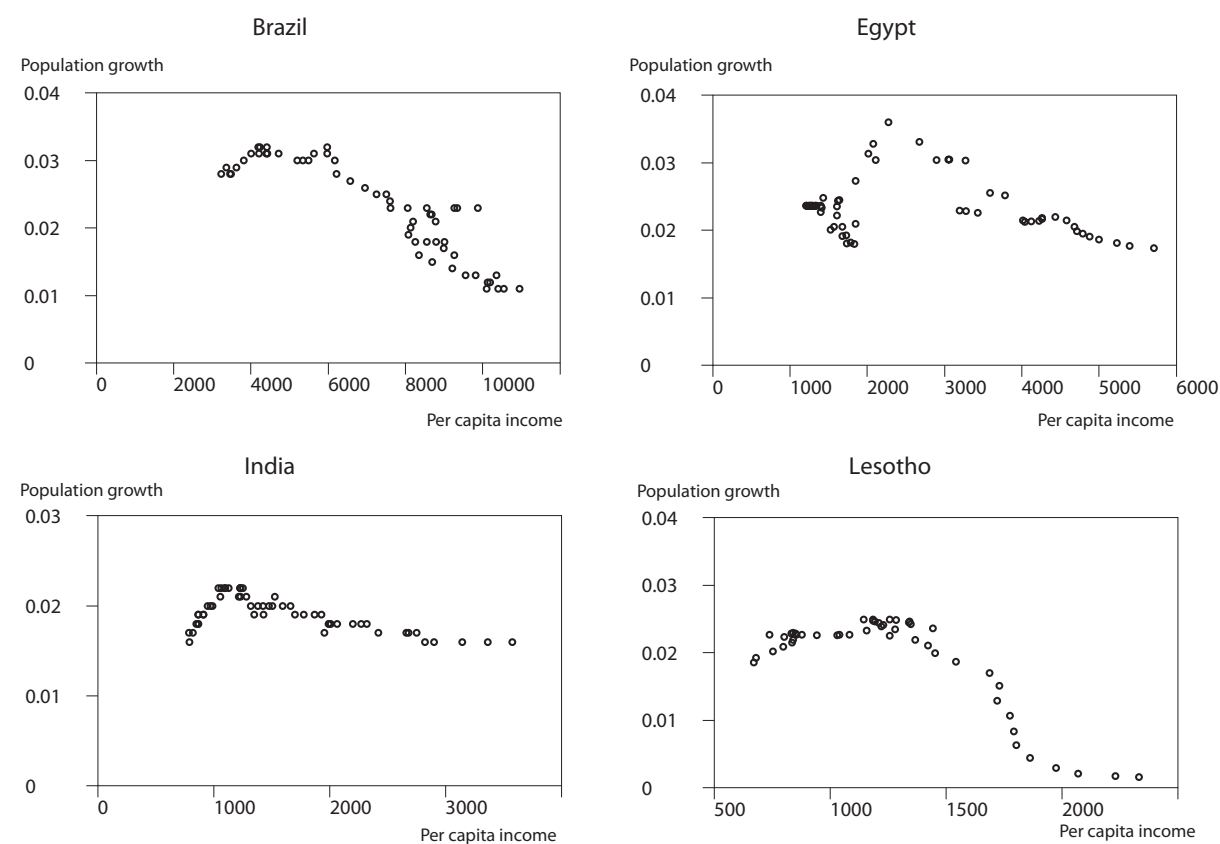

Figure 1: Population growth. Sources: US Census Bureau (2010); Heston et al. (2009)

This paper, which is on the economic consequences of the demographic transition, collects and summarizes these theories on the simple assumption that the population growth rate is a hump-shaped function of income. ${ }^{1}$ Undeniably, the empirical association between income and population growth

\footnotetext{
${ }^{1}$ Hansen and Prescott (2002) adopt a closely related solution by taking fertility as a piece-wise linear function of per capita consumption.
} 
is the subject of an ongoing debate as historical statistics are far from satisfactory (Bonneuil, 2010). But it is possible to find reliable data from developing countries currently in the midst of the demographic transition. Figure 1 plots the annual population growth rates from 1950 to 2007 against per capita incomes in four countries, showing a hump-like association in each case. ${ }^{2}$ However, because it is not known how current observations generalize to historical data, this paper concentrates on the recent consequences of the demographic transition.

The demographic transition in the otherwise standard Ramsey model can generate multiple equilibria, poverty traps, and demography-driven transitional cycles. ${ }^{3}$ The solution of the model depends on three demographic parameters - the income elasticity of the population growth rate, the income level at which population growth peaks, and the height of this peak. The calibrated version shows that three types of transition can arise. ${ }^{4}$ In the first type, the values of all demographic parameters are low, implying that the equilibrium (steady state) is unique, while multiple equilibria arise for excessively high values, leading the economy toward a low-income poverty

\footnotetext{
${ }^{2}$ Similar figures are seen in many other developing countries, but civil wars, missing data, etc. make this sort of exercise difficult in some cases.

${ }^{3}$ Some other modifications of the neoclassical Ramsey model introduce productive externalities, variable demand elasticities, and market imperfections to generate multiequilibrium models (Azariadis and Drazen, 1990; Matsuyama, 1991; Benhabib and Farmer, 1994; Benhabib and Gali, 1995; Gali, 1996). For earlier demographic multiplicity, see Galor and Weil (1996); (2000); Kremer and Chen (2002); Cervellati and Sunde (2005), for example.

${ }^{4}$ Earlier calibrated versions of demo-economic models are Hansen and Prescott (2002), de la Croix and Doepke (2003; 2004), Doepke (2004), Lagerlöf (2006), Bar and Leukhina (2010), and Jones and Schoonbrodt (2010). These papers concentrate on historical data from Europe and U.S.. Applied techniques are also different, since this paper provides a model in continuous time, thus indicating annual population growth rates, whereas the other papers are based on discrete models in which the time unit is one generation.
} 
trap. In the intermediate case, the low-income steady state is present but the economy is still able to proceed toward the high-income steady state experiencing, however, a sizeable variation in its economic growth. These cases are denoted Weak, Strong, and Intermediate respectively. The calibrations show that the high-income steady state can provide twice as much income as the low-income steady state and the demography-driven variation in economic growth can explain the long-lasting recessions recently observed in many developing countries. Nevertheless, permanent poverty-traps are not typical.

The paper has the following organization: Section 2 introduces the modified Ramsey model and its solution, discussing some mathematical details in the Appendix. Section 3 provides a calibrated version and a parametric bifurcation analysis, and quantifies the importance of the multiple equilibria. Section 4 closes the paper.

\section{The Demographic Transition in the Ram- sey Model}

\subsection{Income, Utility, and the Demographic Transition}

Consider an economy with capital $K$, population $L$, per head capital $k(t)=$ $K / L$, and per head production function $y=f(k)$, which satisfies the Inada conditions $\lim _{k \rightarrow 0} f^{\prime}(k)=\infty, \lim _{k \rightarrow \infty} f^{\prime}(k)=0, \lim _{k \rightarrow 0} f(k)=0$, and is strictly concave $\left(f^{\prime}>0, f^{\prime \prime}<0\right)$.

The standard Ramsey model assumes that the population growth rate $\dot{L} / L=n$ is constant but, to introduce the demographic transition, we assume that population growth is a function of income per head $y$ such that it initially 
accelerates and then slows down. Because per head income is monotonic in terms of capital $\left(f^{\prime}>0\right)$, we write population growth as a function of the latter. ${ }^{5}$ Hence, the population function $n=n(k)$ assumes

$$
\begin{aligned}
& n^{\prime}(k)>0 \Leftrightarrow k<\mu, \\
& n^{\prime}(k)=0 \Leftrightarrow k=\mu, \\
& n^{\prime}(k)<0 \Leftrightarrow k>\mu,
\end{aligned}
$$

where the capital stock $k=\mu>0$ is the stock from which population growth keeps decreasing. Figure 2 illustrates. Given that the demographic transition typically occurs at low income levels, the capital stock $k=\mu$ must be lower than what is seen in the industrial countries currently.

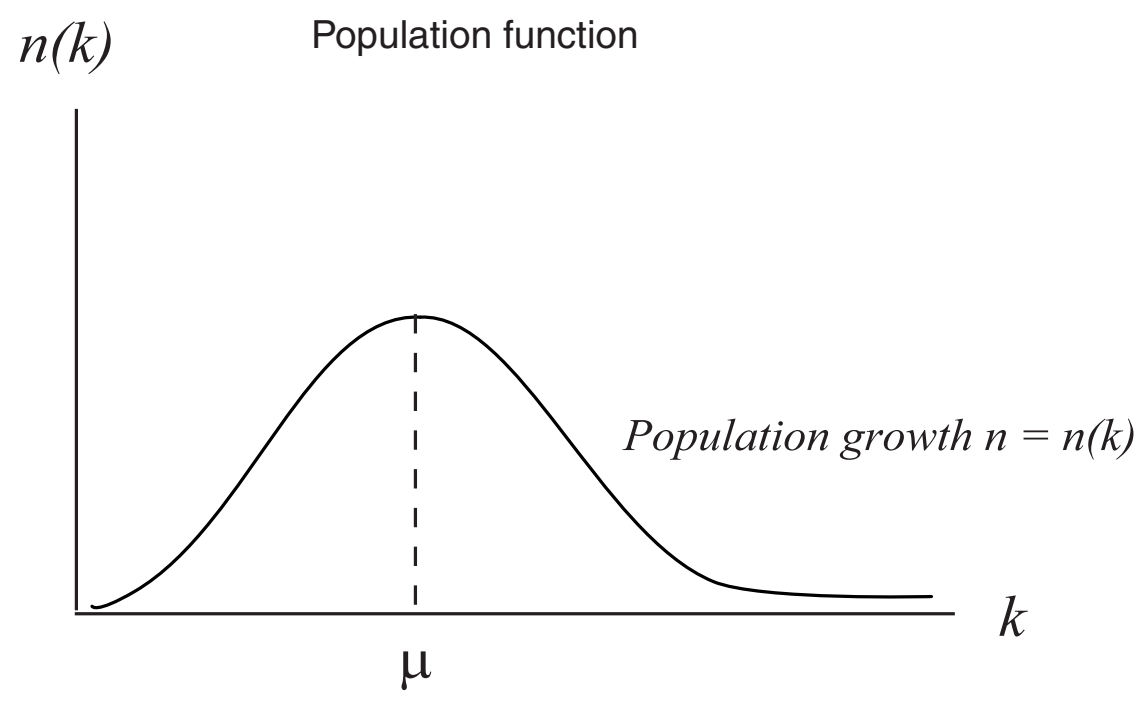

Figure 2: Population growth as a function of income.

Furthermore, because population growth initially accelerates slowly and ultimately levels off, we assume the limit conditions

$$
\begin{aligned}
& \lim _{k \rightarrow 0}\left\{n^{\prime}(k)\right\}<\infty, \\
& \lim _{k \rightarrow \infty}\left\{n^{\prime}(k)\right\}=0 .
\end{aligned}
$$

\footnotetext{
${ }^{5}$ This formulation has already been suggested by Solow in the extensions of his famous 1956 model (Solow, 1956). It was also applied by Lane (1975), who considered the case in which population growth accelerates.
} 
Defined in this way, $n=n(k)$ is in line with the data and the micro foundations above. Normalizing the initial population to unity, the population size at time $t$ becomes

$$
L(t)=\exp \left\{\int_{0}^{t}\{n[k(\tau)]\} d \tau\right\} .
$$

Consider now a central planner who maximizes the Benthamian function $U=\int_{0}^{\infty} u[c(t)] \cdot L(t) \cdot e^{-\rho t} d t$, where utility is derived from per head consumption $c$ and from the number of people $L$, the temporary utility $u[c(t)] \cdot L(t)$ being discounted by the subjective time preference rate $\rho>0$. With constant population growth $n, L(t)=e^{n t}$ holds and the integrand above becomes $u[c(t)] \cdot e^{-(\rho-n) t}$. But if $n=n(k)$, it holds that

$$
U=\int_{0}^{\infty} u[c(t)] \cdot \exp \left\{-\int_{0}^{t}\{\rho-n[k(\tau)]\} d \tau\right\} d t
$$

Since the Benthamian formula refers to the discounted total utility, $U$ increases forever for $n$ sufficiently high. To keep Eq. (4) bounded, one has to assume $\rho-n(k)>0$ keeping the effective discount rate positive for all $k$. In a closed economy, the per head capital accumulates according to

$$
\dot{k}=f(k)-c-[\delta+n(k)] k,
$$

where $\delta>0$ stands for depreciation. The only modification in Eq. (4) - (5) is that the population growth rate is not constant but responds endogenously to the capital stock chosen by the planner.

\subsection{The Solution of the Modified Model}

Eq. (4) - (5) give an infinite horizon problem with variable discount rate. To solve this problem, we follow the procedure suggested by Uzawa (1968) and 
move from the natural time $t$ to the virtual time $\Delta(t)$ as defined by

$$
\Delta(t)=\int_{0}^{t}\{\rho-n[k(\tau)]\} d \tau
$$

This implies $\frac{d \Delta(t)}{d t}=\rho-n[k(t)]>0$ and $\Delta(0)=\int_{0}^{0}\{\rho-n[k(\tau)]\} d \tau=0$, so that $\Delta(t)$ satisfies the regularity conditions suggested by Uzawa (1968). By utilizing the fact that $d t=d \Delta /(\rho-n)$, the problem in Eq. (4) - (5) can now be written in terms of $\Delta$ :

$$
\begin{aligned}
U & =\int_{0}^{\infty} \frac{u[c(t)]}{\rho-n[k(t)]} e^{-\Delta(t)} d \Delta(t), \\
\frac{d k(t)}{d \Delta(t)} & =\frac{f[k(t)]-c(t)-(\delta+n[k(t)]) k(t)}{\rho-n[k(t)]} .
\end{aligned}
$$

Since the discount factor in Eq. (7) - (8) is constant, it can be solved by standard methods (Uzawa, 1968; Lane, 1975). The current value Hamiltonian and the necessary conditions become:

$$
\begin{aligned}
H(k, c, \lambda) & =\frac{1}{\rho-n}\{u+\lambda(\Delta)[f-c-(\delta+n) k]\}, \\
\partial H / \partial c & =0 \Leftrightarrow u^{\prime}=\lambda, \\
\frac{d \lambda(\Delta)}{d \Delta} & =-\frac{\partial H(k, c, \lambda)}{\partial k}+\lambda(\Delta),
\end{aligned}
$$

where $n=n[k(t)]$ and $u=u[c(t)]$ etc. Noting Eq. (6), Eq. (11) reverts back to natural time by writing $\dot{\lambda} \doteq \frac{d \lambda}{d \Delta} \frac{d \Delta}{d t}=(\rho-n)\left\{-\frac{\partial H(k, c, \lambda)}{\partial k}+\lambda\right\}$. Noting Eq. (10), one can eliminate $\lambda$ in the usual way and, after some algebra, the differential equation for consumption becomes

$$
\frac{\dot{c}}{c}=\frac{-u^{\prime}}{u^{\prime \prime} \cdot c}\left\{f^{\prime}-(\delta+\rho)-n^{\prime} \cdot k+\frac{n^{\prime}}{u^{\prime}} H(k, c)\right\},
$$


where $H(k, c)=\frac{1}{\rho-n}\left\{u+u^{\prime}[f-c-(\delta+n) k]\right\}$ is the optimized Hamiltonian and $n^{\prime}$ refers to the response of the population growth rate to the change of the capital stock.

The equation for consumption is easier to handle if one adopts the CIES formula $u(c)=\frac{c^{1-\theta}}{1-\theta}$, which has the convenient property $\frac{-u^{\prime}(c)}{u^{\prime \prime}(c) c}=\frac{1}{\theta}$ under the assumptions $\theta>0$ and $\theta \neq 1 .^{6}$ In this case, the optized Hamiltonian is $H(k, c)=\frac{1}{(\rho-n)}\left\{\frac{c^{1-\theta}}{(1-\theta)}+c^{-\theta}[f-c-(\delta+n) k]\right\}$ and the differential equation for consumption becomes

$$
\frac{\dot{c}}{c}=\frac{1}{\theta}\left\{f^{\prime}-(\delta+\rho)-n^{\prime} \cdot k+\frac{n^{\prime}}{(\rho-n)}\left[\frac{\theta c}{(1-\theta)}+[f-(\delta+n) k]\right]\right\} .
$$

The isoclines $\dot{c}=0$ and $\dot{k}=0$ in the $k-c$ space are given by

$$
\begin{aligned}
\dot{c} & =0 \Rightarrow c=\frac{\theta-1}{\theta}\left\{\left[f^{\prime}-(\delta+\rho)\right]\left(\frac{\rho-n}{n^{\prime}}\right)+[f-(\delta+\rho) k]\right\}, \\
\dot{k} & =0 \Rightarrow c=f-(\delta+n) k .
\end{aligned}
$$

Given the Inada conditions, the isocline $\dot{k}=0$ runs from the origin intersecting the $k$-axis at $\tilde{k}$ defined by

$$
f(\tilde{k}) / \tilde{k}=\delta+n(\tilde{k})
$$

Even though the production function $f(k)$ is concave, $\dot{k}=0$ can have nonconcave areas since population growth varies together with capital. Figure 5 illustrates. This can be rephrased as follows:

\footnotetext{
${ }^{6}$ For the formula $u(c)=\frac{c^{1-\theta}-1}{1-\theta} \lim \theta \rightarrow 1(c)=\ln c$ holds, but this is not valid for the shorter expression above. Hence the assumption $\theta \neq 1$.
} 

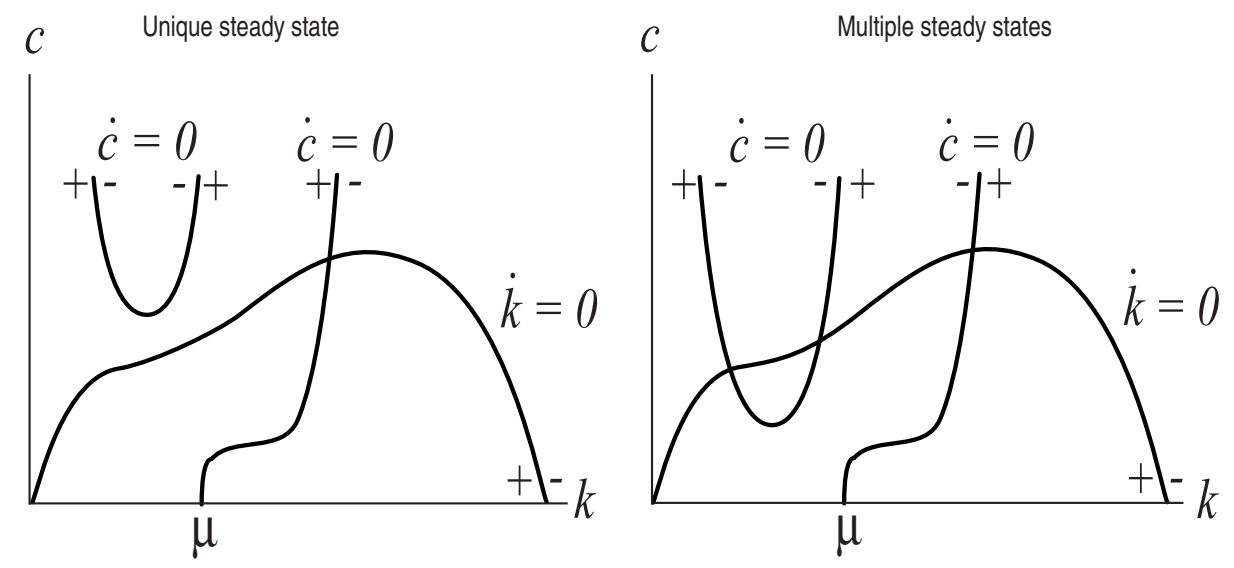

Figure 3: The phase diagrams of the model.

Proposition 1 With $\tilde{k}$ such that $f(\tilde{k}) / \tilde{k}=\delta+n(\tilde{k})$, the $\dot{k}=0$ isocline of the modified Ramsey model

(i) starts from the origin and

(ii) runs above the horizontal axis for $0<k<\tilde{k}$.

The isocline $\dot{c}=0$ in Eq. (13) can have several shapes, depending upon the values of the parameters; we concentrate on the empirically relevant cases. First, note that the shape of $\dot{c}=0$ depends on $\theta$. Since Hall (1988) suggests that high values are empirically plausible, we assume $\theta>1$ implying that the fraction $\frac{\theta-1}{\theta}$ is positive. ${ }^{7}$

Next, consider the limit behavior of the expression $\left[f^{\prime}-(\delta+\rho)\right]\left(\frac{\rho-n}{n^{\prime}}\right)$. Given Eq. (1) - (2), the fraction $\frac{\rho-n}{n^{\prime}}$ goes to a finite positive number as $k$ approaches zero, $+\infty(-\infty)$ as $k$ approaches $\mu$ from the left (right), and $-\infty$ as $k$ approaches $+\infty$. Given the Inada conditions, the expression

\footnotetext{
${ }^{7}$ Although the isocline inverts, the results are unchanged for $\theta<1$.
} 
$\left[f^{\prime}-(\delta+\rho)\right]$ goes from $+\infty$ to $-(\delta+\rho)<0$ and changes its sign at $\hat{k}$ with $f^{\prime}(\hat{k})=(\delta+\rho)$ where $\hat{k}<\tilde{k}^{8}$ The limit behavior of $\left[f^{\prime}-(\delta+\rho)\right]\left(\frac{\rho-n}{n^{\prime}}\right)$ thus depends on the relation between $\mu$ and $\hat{k}$. We assume $\mu<\hat{k}$, implying that population growth peaks at a relatively low level of per head capital, as has been typical. Therefore, $\lim _{k \rightarrow 0}\left\{\left[f^{\prime}-(\delta+\rho)\right]\left(\frac{\rho-n}{n^{\prime}}\right)\right\}=+\infty$, $\lim _{k \uparrow \mu}\{\cdot\}=+\infty, \lim _{k \downarrow \mu}\{\cdot\}=-\infty$, and $\lim _{k \rightarrow \infty}\{\cdot\}=+\infty$. Since the finite element $f-(\delta+\rho) k$ affects $\dot{c}=0$ in the vicinity of the $k$-axis but has no effect on its limit behavior, the isocline $\dot{c}=0$ produces a $U$-shaped graph for $k<\mu$, but swings from $-\infty$ to $+\infty$ for $k>\mu$, as Figure 3 illustrates. This discussion can be rephrased as follows:

Proposition 2 For $\theta>1$ and $\mu<\hat{k}<\tilde{k}$ with $f^{\prime}(\hat{k})=(\delta+\rho)$, the isocline $\dot{c}=0$ of the modified Ramsey model

(i) is $U$-shaped graph for $k<\mu$ and

(ii) swings from $-\infty$ to $+\infty$ for $k>\mu$.

To state the existence of interior steady states, note that Eq. (15) implies that since $\dot{c}=0$ becomes $c=\frac{\theta-1}{\theta}\left\{\left[f^{\prime}(\tilde{k})-(\delta+\rho)\right]\left(\frac{\rho-n}{n^{\prime}(\tilde{k})}\right)\right\}$ for $k=\tilde{k}>\hat{k}>$ $\mu, n^{\prime}(\tilde{k})<0$ and $\left[f^{\prime}(\tilde{k})-(\delta+\rho)\right]<0$, and $c>0$. Hence, $\dot{c}=0$ runs above the horizontal axis for $k=\tilde{k}$ but $\dot{k}=0$ hits this axis. Given the limit behavior of $\dot{c}=0$ as above, this implies that the model has at least one interior steady state. Figure 3 illustrates.

Consider the position of the $U$ part of $\dot{c}=0$ in the phase space [Fig.

${ }^{8}$ The strict concavity of $f(k)$ implies that $f^{\prime}(k)<f(k) / k$ for all $k$. Hence $f(\tilde{k}) / \tilde{k}=$ $\delta+n(\tilde{k})<\delta+\rho=f^{\prime}(\hat{k})$ holds only if $\hat{k}<\tilde{k}$. 
3]. For $U$ high enough, the number of steady states is one. Local stability analysis in Appendix A indicates that this steady state is a saddle. For $U$ tangent to $\dot{k}=0$, a saddle-node bifurcation takes place. ${ }^{9}$ For $U$ low enough, the number of the steady states is three. The low and high-income steady states are saddles with stable paths running from the south-west and northeast. The middle steady state is an unstable focus or node [Appendix A]. The former is assumed but the analysis of the latter is not much different.

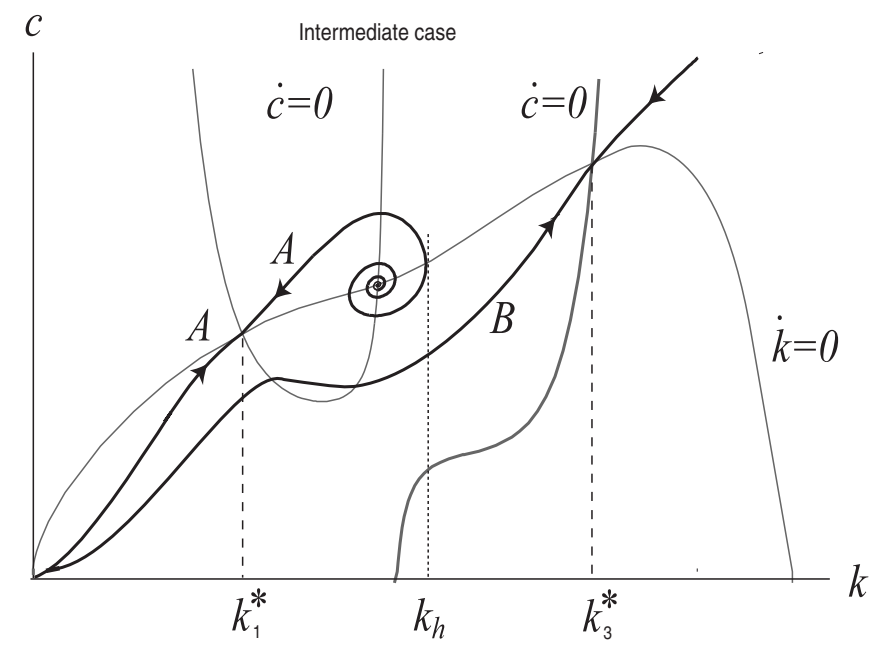

Figure 4: Path $B$ runs from the origin; $k_{1}^{*}$ and $k_{3}^{*}$ are the low and highincome steady states, capital stock $k_{h}$ is the highest initial stock from which the low-income steady state can be reached.

In the case of three steady states, the saddle path $B$ can adopt at least two alternative shapes, i.e., it may run from the origin [Fig. 4] or emanate from the middle steady state [Fig. 5]. ${ }^{10}$ In the former case, the high-income steady

\footnotetext{
${ }^{9}$ This non-generic is not analyzed below. Non-concavities of the isoclines imply that further steady states cannot be excluded a priori. I concentrate on the cases depicted in Figure 3.

${ }^{10}$ Since the case, in which the north-eastern branch of $A$ runs non-spiralling (Matsuyama, 1991; Gali, 1996) does not appear in the parametric model below, I bypass it here.
} 
state is reachable from all initial states, but in the latter, the capital stock must be at least $k_{m} \in\left(k_{l}, k_{h}\right)$ initially. Hence, there exists a poverty trap, implying that a country with the initial capital stock lower $k_{m}$ never reaches the high-income steady state. For the complete solution of the problem, see Appendix B. The discussion above can be summarized as follows:

Proposition 3 Given Propositions (1) and (2), the modified Ramsey model

(i) has at least one saddle stable steady state $0<k^{*}<\tilde{k}$,

(ii) may have three steady states $k_{1}^{*}, k_{2}^{*}, k_{3}^{*}$ (saddle, unstable focus, saddle) in which case either
a $\lim _{t->\infty} k(t)=k_{3}^{*} \forall k(0)>0$ or
b $\lim _{t->\infty} k(t)=k_{1}^{*} k(0)<k_{m}$ and $\lim _{t->\infty} k(t)=k_{3}^{*} k(0)>k_{m}$.

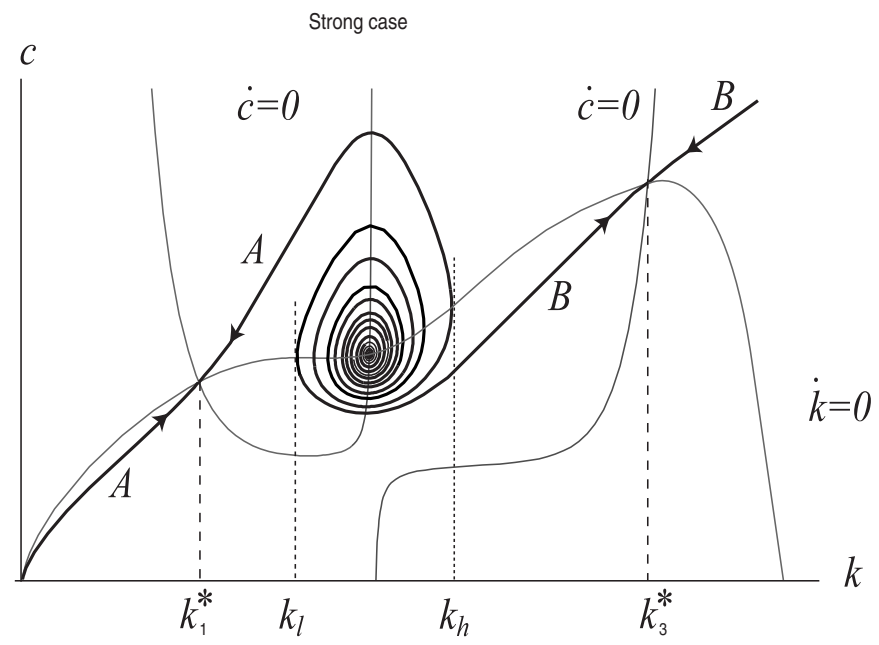

Figure 5: Path $B$ spirals from the middle-income steady state. Capital stock $k_{l}$ is the lowest initial stock from which the high-income steady state can be reached. 


\section{The Calibrated Model}

Since the modified Ramsey model above exhibits potential for multiple steady states, one wants to know the demographic conditions under which this multiplicity holds true. Therefore, we now calibrate the model for global data.

Consider first the parametrization of the population function. Several expressions satisfy the basic assumptions in Eq. (1), but only a few meet the requirement $\lim _{k \rightarrow 0}\left\{n^{\prime}[k(t)]\right\}<\infty, \lim _{k \rightarrow \infty}\left\{n^{\prime}[k(t)]\right\}=0$ given in Eq. (2). A formula satisfying both is the three-parametric expression

$$
n(k)=\eta \cdot \exp \left\{-\frac{1}{2}\left(\frac{k-\mu}{\sigma}\right)^{2}\right\},
$$

in which $\eta, 1 / \sigma$, and $\mu$ are the peak population growth rate, the income elasticity of population growth, and the peak-time per head capital respectively [Fig. 2].

To calibrate Eq. (16), note that the observed peak population growth rates range from 0.01 to 0.045 (Livi-Bacci, 1997, US Census Bureau, 2010). Hence, let $0.01 \leq \eta \leq 0.045$. To find the limits for $\mu$, one can utilize Prescott (1998), who argues that economic miracles occur when countries reach the per head GDP level which is approximately $25 \%$ of that in the U.S. To calculate $k_{U S A}$, the investment time series for the period 1950-2005 from the U.S. was collected (data from Heston et al., 2009) and the perpetual inventory method (Caselli, 2004) was applied to show that the per head capital stock in the U.S. in 2005 was $\$ 132599,25 \%$ of which is thus a candidate for $\mu$. However, to keep the numbers simple we let $\mu=\$ 30000$. This $\mu$ is denoted as $1 / 4 k_{U S A}$ in the text and graphs. In the sensitivity analysis, we allow $\mu$ to vary from $1 / 4 k_{U S A}-\$ 3000$ to $1 / 4 k_{U S A}+\$ 3000$. Given this $\mu$, the limits $20000 \leq$ 
$\sigma \leq 10000$ have been chosen for the (inverse of the) income elasticity of population growth. These limits allow the demographic transition to get started and mature in a realistic way. Table 1 summarizes.

\begin{tabular}{ll}
\hline \hline Parameter & Explanation \\
\hline$\alpha=1 / 3$ & Share of capital \\
$A=300$ & Total factor productivity \\
$\rho=0.045$ & Preference factor \\
$\theta=3$ & Negative of the elasticity of marginal utility \\
$\delta=0.05$ & Depreciation rate \\
$0.01 \leq \eta \leq 0.045$ & Peak population growth rate \\
$20000 \leq \sigma \leq 10000$ & The (inverse of) income elasticity \\
$\mu=30000=1 / 4 k_{U S A}$ & Peak-time per head capital, in 2005 U.S. dollars \\
\hline
\end{tabular}

Table 1: The values of the parameters.

For the production technology, the Cobb-Douglas formula $y=A k^{\alpha}$ is applied with $\alpha=1 / 3$. The parameter $A$ varies between countries and in time, but Hall and Jones (1999) find that the total factor productivity in developing countries typically ranges from $30 \%$ to $60 \%$ of that in the U.S. Given $\alpha=1 / 3$ and $k_{U S A}$ as above, and noting the per head U.S. income of $\$ 41870$ in 2005 , one can derive $A_{U S A}=826$. Thus, $A=300$ should be an appropriate value for a developing country. A combination of these parameters shows that the peak-time per head income is approximately $25 \%$ of that in the U.S., which is in line with Prescott (1998). Further, we choose $\theta=3 \delta=0.05$, and $\rho=0.045$; these values are close to those suggested by Barro and Sala-i-Martin (1995) [Table 1]. All parameter combinations meet the parameter constraints mentioned in the theoretical text.

It is now possible to calculate the type of solution for each feasible combination of $\eta, \sigma$, and $\mu$. The middle panel in Figure 6, drawn for $\mu=30000$, 


\section{Bifurcation analysis}
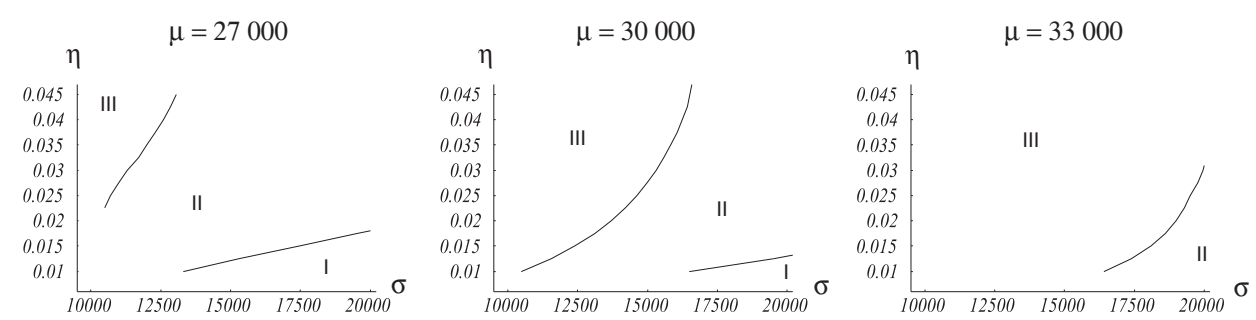

Figure 6: Effect of the parameters in the calibrated model. Range I: single steady state. Range II: three steady states; path B runs from the origin. Range III: three steady states; path B emanates from the middle-income steady state. Sources: US Census Bureau (2010); Heston et al. (2009).

shows the two curves which divide the $(\sigma, \eta)$ space into three ranges indicating a single steady state (I), three steady states with path $B$ from the origin (II), and three steady states with path $B$ from the middle-income steady state alone (III).

In range $I$, the values for $\eta$ and $1 / \sigma$ are low, whereas the opposite is true in range $I I I$. In the former, population growth keeps low and is insensitive to income, so that the demographic transition proceeds without causing much harm to the economy for which reason it is denoted as Weak. In range III, high peak population growth makes capital deepening hard and each unit of investment induces an aggressive increase in population growth, thus taking the economy into a low-income poverty trap. Therefore, this type of the demographic transition is denoted as Strong. In the Intermediate case (range $I I$ ), the low-income steady state arises but the economy is still able to proceed toward its high-income steady state. Comparison of the panels in Figure 6 shows the role of $\mu$ : the probability of the poverty trap increases as $\mu$ increases because lower marginal productivity endangers capital deepening. 
To give an example of each type, one can choose a set of preferred parameters such that they lie approximately in the middle of each parameter range. Figure 7 shows the population functions $n(k)$ for such a set of parameters. ${ }^{11}$

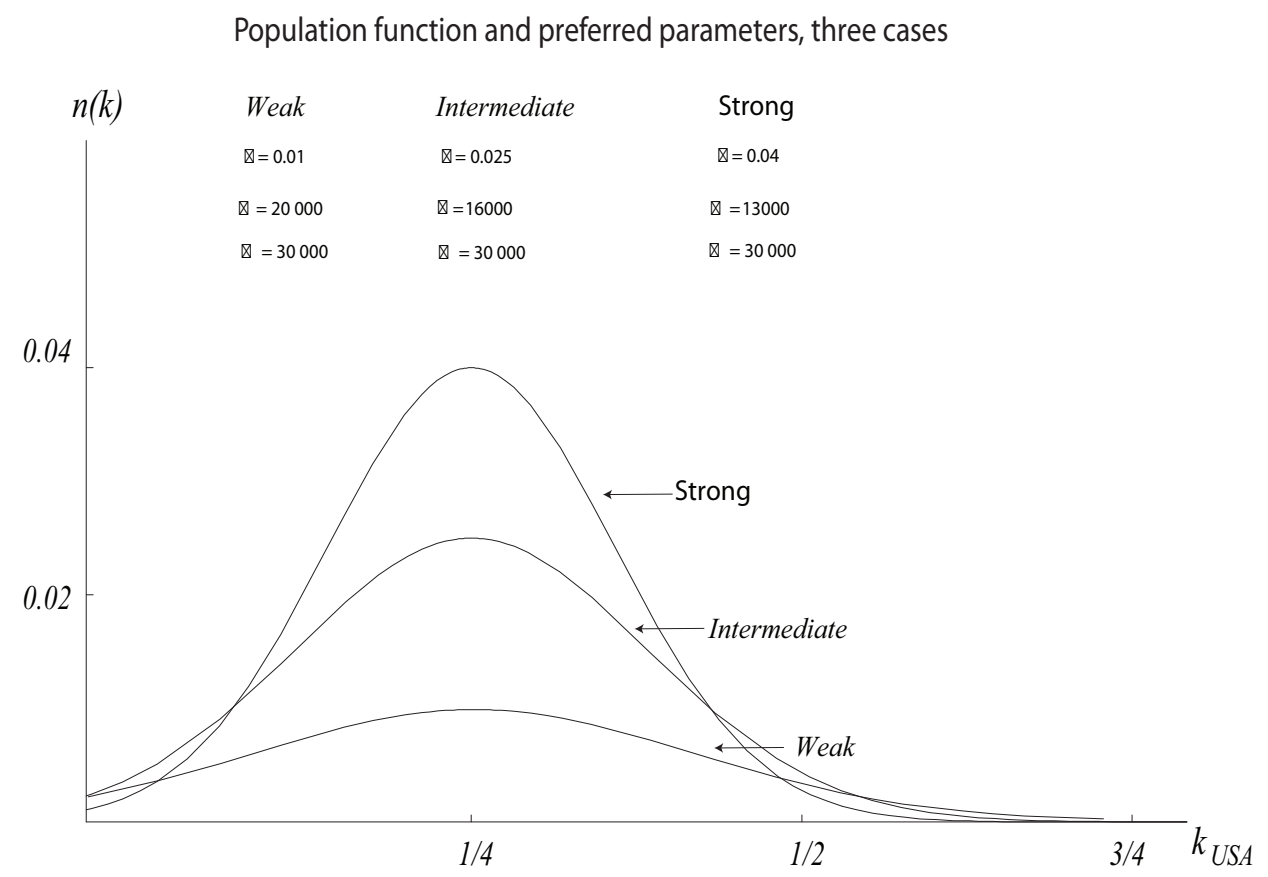

Figure 7: The preferred parameters and associated population functions.

Consider now the steady state implications of the calibrated model. An often-heard suggestion is that international aid should be applied to elevate the poorest countries out of poverty. To evaluate the effects of such a policy, consider a Strong country with preferred parameters as in Figure 7. In the low and high income steady states, $k_{1}^{*}=9329$ and $y_{1}^{*}=A k_{1}^{\alpha}=6315$ versus $k_{3}^{*}=65475$ and $y_{3}^{*}=A k_{3}^{\alpha}=12092$ holds, implying that the high-to-low income ratio is $y_{3}^{*} / y_{1}^{*}=1.91$. Thus, if this country could switch from its low

\footnotetext{
${ }^{11}$ The Mathematica program for drawing figures $1-9$ and to calculate the parametric results is available from the author on request.
} 
to its high-income steady state, its income would approximately double. ${ }^{12}$ To evaluate the sensitivity of the high-to-low income ratio to the demographic parameters, let one of them vary within the Strong range and keep the two others as preferred. ${ }^{13}$ Figure 8 shows that the $y_{3}^{*} / y_{1}^{*}$ ratio increases together with $\sigma$ and $\eta$ and decreases with $\mu$ but this sensitivity is very limited in all cases, Table 2 indicates that the lowest and highest ratios are 1.64 and 2.04. One can now compare these findings with the observed global income gap showing that, in 2005, the richest decile earned forty times as much as the poorest (184 countries from Heston et al., 2009). Therefore, even though an individual poor country would greatly benefit from a switch to its highincome steady state, the effects of such switches on the global income gap would be rather limited.

The high-to-low income ratio, the Strong case
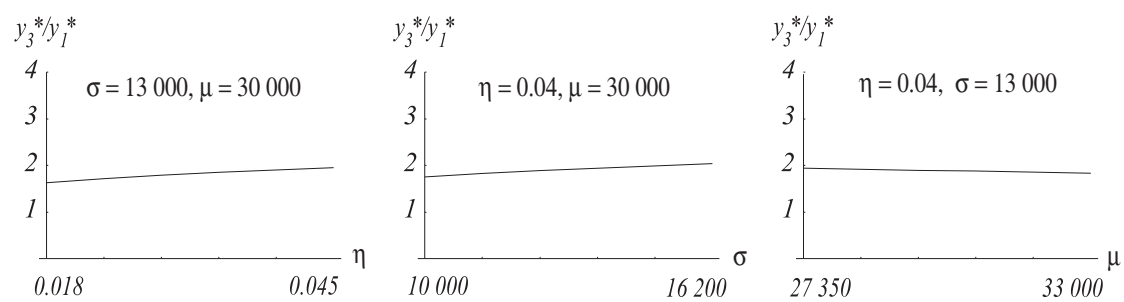

Figure 8: The high-to-low income ratio $y_{3}^{*} / y_{1}^{*}$ as a function of demographic parameters $\eta, \sigma$, and $\mu$ within the Strong range; range limits shown for each parameter. Sources: as for Figure 5.

\footnotetext{
${ }^{12}$ This finding is in line with that of Graham and Temple (2006), who calculate that a switch from a low- to high-income steady state would increase a country's income by a factor two or three on average.

${ }^{13}$ Each parameter increases in five steps of equal step length within the appropriate parameter range, the limits of which are shown in Figure 8.
} 
Consider then the off-steady state implications of the model. The standard Ramsey model predicts that the economic growth rate always decreases. Figure 9, which shows the time paths for economic growth rates, indicates that this rule is true only for the Weak and Strong countries, whereas the Intermediate country meets a sizeable transitional cycle in its way to its high-income steady state. With the preferred parameters, it takes 16 years to proceed from the bottom to the peak to reach a 0.65 percentage points higher economic growth rate than previously [Table 2].

Time paths of economic growth rates, preferred parameters

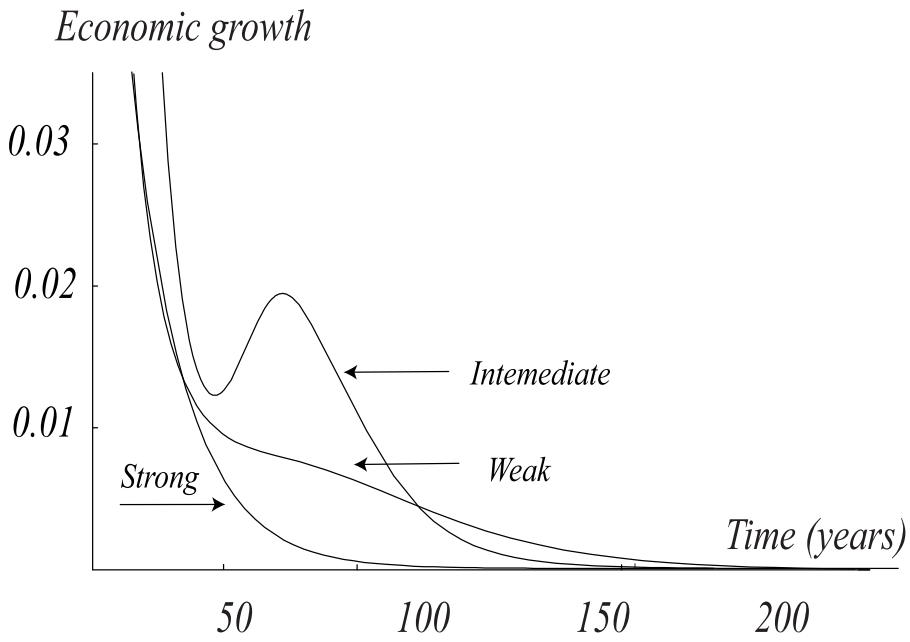

Figure 9: The transitional growth rates of the per head income for the preferred parameters. Sources: as for Figure 5.

A sensitivity analysis shows that an increase in the peak population growth rate $\eta$ increases both the amplitude and duration of the transitional cycle [Fig. 10, leftmost panel]. The cycle escalates when $\eta$ approaches the upper limit of the Intermediate parameter range and it ultimately takes almost 20 years to proceed from the bottom to the peak, with more than 2 
percentage points higher economic growth rate. In particular, the period of deep depression gets longer since the low-income steady state (the poverty trap) keeps the economy tightly in its freezing grasp, but the economy recovers rapidly thereafter. Analogous results are provided for parameters $\sigma$ and $\mu$ [Fig. 10]. Table 2 collects these results, showing that there is a considerable variation both in the duration and amplitude of the demography-driven transitional cycle. ${ }^{14}$ To compare these findings again with the data, note that the average annual economic growth rates from 1995 to 2005 in the fastest and slowest growing deciles were $8.38 \%$ and $-1.82 \%$ (188 countries from Heston et al., 2009), implying that the maximum demographic growth impact of $2.22 \%$ is able to explain $20 \%$ of the observed growth differentials worldwide. $^{15}$

\begin{tabular}{lccc}
\hline \hline & Preferred & Lowest & Highest \\
\hline High-to-low income ratio $\left(y_{3}^{*} / y_{1}^{*}\right)$ & 1.91 & 1.64 & 2.04 \\
Duration of the cycle from bottom to peak (years) & 16 & 0 & 20 \\
Growth rate differential from bottom to peak $(\%)$ & 0.65 & 0 & 2.22 \\
\hline
\end{tabular}

Table 2: Summary of the calibrated model.

Given the potentially long time-span of the recession, it is hard to say whether a badly performing country is trapped or just recessed. Fortunately, the present model provides a simple test because the low-income equilibrium $k_{1}^{*}$ is always located left of $\mu$ [Fig. 5], indicating that an economy which has reached its demographic peak has already avoided the trap. Consider, for example, the 36 countries which, based on their low economic growth rate

\footnotetext{
${ }^{14}$ The lowest limits of 0 indicate that the transitional cycle may be just a plateau in the otherwise decreasing growth trend.

${ }^{15}$ Bloom and Williamson (1998) suggest that population dynamics can explain 1.37-1.87 percentage-units of the East Asian economic miracles.
} 
Sensitivity of the transitional cycles to demographic parameters
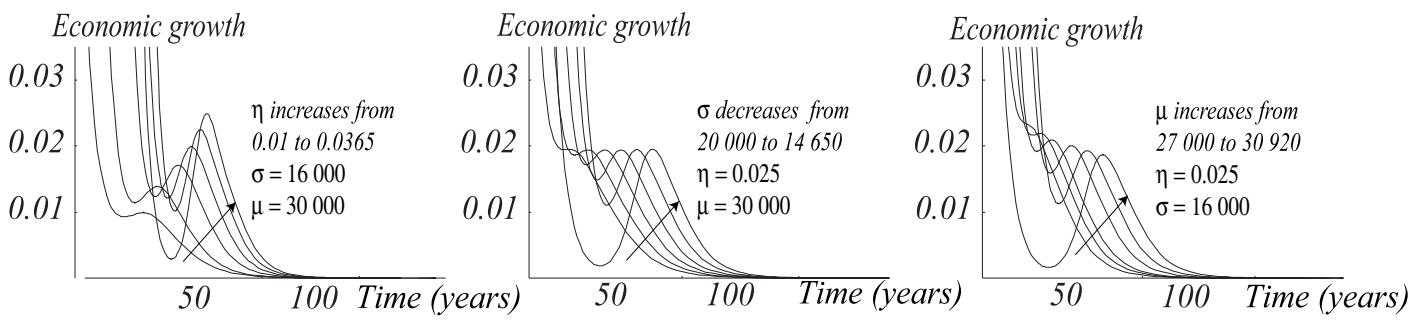

Figure 10: The transitional growth rates of the per head income as a function of demographic parameters $\eta, \sigma$, and $\mu$ within the Intermediate range; range limits shown for each parameter. Sources: as for Figure 5.

thus far, have been classified as trapped by Graham and Temple (2006). Of these, at least 16 have experienced a clear-cut demographic peak recently. These countries, the peak years, and the peak population growth rates are given in Table $3 .{ }^{16}$ In terms of these countries, the predictions of the current model are much more optimistic than those given by Graham and Temple (2006).

\begin{tabular}{lll|lll}
\hline \hline Country & Peak year & Pop. growth & Country & Peak year & Pop. growth \\
\hline Angola & 1995 & 2.21 & Niger & 1981 & 2.83 \\
Burkina Faso & 1988 & 3.16 & Papua N. G. & 1994 & 2.56 \\
Central Africa & 1988 & 2.83 & Senegal & 1980 & 3.12 \\
Chad & 1995 & 3.08 & Sierra Leone & 1992 & 2.54 \\
Congo (Zaire) & 1988 & 3.10 & Tanzania & 1989 & 3.02 \\
Gambia & 1990 & 3.06 & Togo & 1988 & 3.56 \\
Guinea-Bissau & 1990 & 2.40 & Zambia & 1980 & 3.35 \\
Mozambique & 1989 & 2.96 & Zimbabwe & 1984 & 3.91 \\
\hline
\end{tabular}

Table 3: Countries which have reached their demographic peaks, peak year and peak population growth rate (rate of natural increase). Sources: US Census Bureau (2010).

The analysis above comes with some caveats. The theoretical model as-

\footnotetext{
${ }^{16}$ In the remaining countries, population growth still increases, there seem to be several peaks, data is insufficient, etc.
} 
sumes that population is equal to the labor force, but actually the populationlabor ratio varies during the demographic transition as the cohort of children, workers, and retirees swells in successive order, amplifying the economic effects of the transition (Bloom and Williamson, 1998). The assumption of identical technologies and taste also limits the analysis since Weak, Intermediate and Strong countries may differ in their technology and taste. Elaborations in these terms would increase the functionality of the present model and make its predictions more accurate.

\section{Conclusion}

This paper introduces the demographic transition into the Ramsey model, revealing its potential for multiple steady states, poverty traps, and demographydriven transitional cycles, and analyzes the demographic conditions under which these are realized. Since the population growth rate is assumed to be a hump-shaped function of income, three types of the demographic transition arise depending on the peak population growth rate, on the income elasticity of population growth, and on the income level at which this transition takes place. These are all low in the Weak type, where the steady state is unique and the demographic transition proceeds without causing any marked economic effects. In the Strong type, all are high, thus taking the economy into a low-income poverty trap. The poverty trap arises in the Intermediate type, but the economy is able to avoid it and proceeds toward its high-income steady state, experiencing, however, a sizeable variation in its economic growth.

An often-heard suggestion is that international aid should be applied to 
elevate the poorest countries out of poverty. This paper shows that a shift of a trapped county (of Strong type) from its low to its high-income steady state would increase its income by a factor of two. Nevertheless, the demographydriven transitional cycle (in the Intermediate countries) is another reason for poverty, as this cycle may last several decades and imply growth differentials above two per cent. Given the long time-span of the cycle, it is hard to say whether a badly performing country is trapped or just suffering from a long-lasting recession but this paper provides a test to discriminate between these two. This test suggests that most poor countries are already on the way toward greater prosperity as they have reached their demographic peaks recently, implying that they should recover in the closest future. This oncefor-all demographic growth impact, even though important, may alone be insufficient to close the global income gap. Instead, it is a good reason for a simultaneous fight against other growth obstacles, to generate favorable conditions for a take-off. A good understanding of the economic consequences of the demographic transition is thus essential, not only to predict but also to act. 


\section{A Appendix: Local Stability of the Steady States}

Consider the system in Eq. (5) and Eq. (12) [Fig. 3]. In a steady state, $\dot{k}=\dot{c}=0$ and Eq. (13)-(14) imply

$$
f^{\prime}-(\delta+\rho)-n^{\prime} k=\frac{n^{\prime}}{(\theta-1)(\rho-n)}\{f-(\delta+n) k\} .
$$

To simplify notations, write $\dot{k}=\varphi(k, c)$ and $\dot{c}=\phi(k, c)$. The Jacobian of the system is

$$
J=\left[\begin{array}{ll}
\partial \varphi / \partial k & \partial \varphi / \partial c \\
\partial \phi / \partial k & \partial \phi / \partial c
\end{array}\right]
$$

The elements of the Jacobian are

$$
\begin{aligned}
\partial \varphi / \partial k & =f^{\prime}-(\delta+n)-n^{\prime} k \\
\partial \varphi / \partial c & =-1, \\
\partial \phi / \partial k & =\frac{c}{\theta}\left\{\begin{array}{c}
\left.f^{\prime \prime}-\left(n^{\prime \prime} k+n^{\prime}\right)+\frac{n^{\prime \prime}(\rho-n)+\left(n^{\prime \prime}\right)^{2}}{(\rho-n)^{2}}\left[\frac{\theta c}{1-\theta}+f-(\delta+n) k\right]\right\} \\
+\frac{n^{\prime}}{\rho-n}\left[f^{\prime}-(\delta+n)-n^{\prime} k\right]
\end{array}\right\}, \\
\partial \phi / \partial c & =\frac{1}{\theta}\left\{f^{\prime}-(\delta+\rho)-n^{\prime} k+\frac{n^{\prime}}{\rho-n}[f-(\delta+n) k]\right\}+\frac{2 n^{\prime} c}{(1-\theta)(\rho-n)} \\
& =\frac{-n^{\prime}}{(\theta-1)(\rho-n)}[f-(\delta+n) k],
\end{aligned}
$$

where $\partial \phi / \partial c$ is derived from Eq. (17) and Eq. (14). As $\partial \phi / \partial k$ contains the unknown second derivative $n^{\prime \prime}$, immediate calculation of the determinant is not possible. Instead, we utilize the fact that the slope of the $\dot{k}=0$ line is $\frac{d c}{d k}=-\frac{\partial \varphi / \partial k}{\partial \varphi / \partial c}$ and that of $\dot{c}=0$ is $\frac{d c}{d k}=-\frac{\partial \phi / \partial k}{\partial \phi / \partial c}$. Hence, one can write

$$
\begin{aligned}
D E T & =(\partial \varphi / \partial k) \cdot(\partial \phi / \partial c)-(\partial \phi / \partial k) \cdot(\partial \varphi / \partial c) \\
& =\left[\left(-\frac{\partial \varphi / \partial k}{\partial \varphi / \partial c}\right)-\left(-\frac{\partial \phi / \partial k}{\partial \phi / \partial c}\right)\right](-\partial \varphi / \partial c) \cdot(\partial \phi / \partial c),
\end{aligned}
$$


where the formula in the square brackets is the difference in the slopes of $\dot{k}=0$ and $\dot{c}=0$ and $(-\partial \varphi / \partial c)=1$. Given Eq. (15) and the assumption $\rho>n$, the expression $f(k)-[\delta+n(k)] k$ is positive for $k<\tilde{k}$, and the sign of $\partial \phi / \partial c$ is that of $-n^{\prime}(k)$. Consider the low-income steady state $k_{1}^{*}$ where $\dot{k}=0$ hits $\dot{c}=0$ from below making the expression in the square brackets positive. As $-n^{\prime}\left(k_{1}^{*}\right)<0$, we have $D E T<0$ and this steady state is a saddle. In the high-income steady state $k_{3}^{*}, \dot{k}=0$ hits $\dot{c}=0$ from above and the square brackets are negative. As $-n^{\prime}\left(k_{3}^{*}\right)>0$, we have $D E T<0$ and the steady state is a saddle.

In the middle-income steady state, $\dot{k}=0$ hits $\dot{c}=0$ from above but $-n^{\prime}\left(k_{2}^{*}\right)<0$. Hence, $D E T>0$. Consider the trace $T R=\partial \varphi / \partial k+\partial \phi / \partial c$. Given Eq. (17) and $\rho>n$, it holds

$$
\begin{aligned}
T R & =f^{\prime}-(\delta+n)-n^{\prime} k-\frac{n^{\prime}}{(\theta-1)(\rho-n)}[f-(\delta+n) k] \\
& >f^{\prime}-(\delta+\rho)-n^{\prime} k-\frac{n^{\prime}}{(\theta-1)(\rho-n)}[f-(\delta+n) k] \\
& =\frac{n^{\prime}}{(\theta-1)(\rho-n)}[f-(\delta+n) k]-\frac{n^{\prime}}{(\theta-1)(\rho-n)}[f-(\delta+n) k]=0 .
\end{aligned}
$$

Because the sign of $(T R)^{2}-4 D E T$ is unknown, the middle-income steady state is an unstable focus or node.

Consider now the dynamics outside the steady states. Because $\partial \varphi / \partial c=$ -1 , the capital stock increases (decreases) below (above) the $\dot{k}=0$ line. The behavior of consumption is given by $\partial \phi / \partial c=$ $\frac{-n^{\prime}(k)}{(\theta-1)[\rho-n(k)]}\{f(k)-[\delta+n(k)] k\}$. Consumption thus decreases (increases) above (below) the $\dot{c}=0$ line for positive $n^{\prime}(k)$, but increases (decreases) above (below) it for negative $n^{\prime}(k)$ [Fig. 3]. Hence, the stable saddle paths approach low and high-income steady states (the unique steady state) from the south- 
west and north-east.

\section{B Appendix: Full Solution of the Problem}

The central planner chooses $c(t)$ to maximize the value of the program in Eq. (4) - (5). This appendix discusses the planner's choice between the alternative saddle paths $A$ and $B$ [Figs. 4, 5]. ${ }^{17}$ The following lemma confirms that Skiba's theorem (Skiba, 1978) applies for non-constant discount rate problems:

Lemma 1 The value of the program in Eq. (4) - (5) is $H[k(0), c(0)]$ where $c(0)$ lies on a stable saddle path.

Proof. Consider the current value Hamiltonian $H(k, c, \lambda)=H=\frac{1}{\rho-n}(u+\lambda \dot{k})$. The conditions $\frac{\partial H}{\partial c}=0, \dot{\lambda}=(\rho-n)\left(\frac{-\partial H}{\partial k}+\lambda\right)$, and $\dot{k}=(\rho-n) \frac{\partial H}{\partial \lambda}$ imply $\frac{d H}{d t}=\frac{\partial H}{\partial c} \dot{c}+\frac{\partial H}{\partial k} \dot{k}+\frac{\partial H}{\partial \lambda} \dot{\lambda}=\frac{\partial H}{\partial \lambda}(\rho-n) \lambda=\lambda \dot{k}$. Hence

$$
\begin{aligned}
-\frac{d\left(e^{-\Delta(t)} H\right)}{d t} & =-e^{-\Delta(t)}\left[\frac{d H}{d t}-(\rho-n) H\right] \\
& =-e^{-\Delta(t)}[\lambda \dot{k}-(\rho-n) H] \\
& =u \cdot e^{-\Delta(t)} .
\end{aligned}
$$

Recall that $e^{-\Delta(t)}=e^{-\int_{0}^{t}\{\rho-n[k(\tau)]\} d \tau}$, and $e^{-\Delta(0)}=1$, and $\rho>n$. Hence, the value of the program becomes

$$
\begin{aligned}
& \int_{0}^{\infty} u \cdot e^{-\Delta(t)} d t=-\int_{0}^{\infty}\left[e^{-\Delta(t)} \frac{d H}{d t}\right] d t \\
= & H[k(0), c(0), \lambda(0)]-\lim _{t \rightarrow \infty} e^{-\Delta(t)} H[k(t), c(t), \lambda(t)] .
\end{aligned}
$$

Along a stable saddle path $H[k(t), c(t), \lambda(t)]$ tends to a constant so that $\lim _{t \rightarrow \infty} e^{-\Delta(t)} H[k(t), c(t), \lambda(t)]=0$. On a saddle path $\lambda(0)=u^{\prime}[c(0)]$. Hence,

\footnotetext{
${ }^{17}$ For a discussion of some other details, see Lehmijoki (2004).
} 
the value of the program in Eq. (4) - (5) is $\int_{0}^{\infty} u \cdot e^{-\Delta(t)} d t=H[k(0), c(0), \lambda(0)]=$ $H[k(0), c(0)]]$.

Consider the case of spiraling saddle path $B$ [Fig. 5]. The value of the program along $A$ and $B$ should be compared for $k(0) \in\left[k_{l}, k_{h}\right]{ }^{18}$ Consider $H(k, c)=\frac{1}{\rho-n}\left(u+u^{\prime} \cdot \dot{k}\right)$. Then

$$
\frac{\partial H(k, c)}{\partial c}=\left[u^{\prime}+u^{\prime \prime} \dot{k}-u^{\prime}\right] \frac{1}{\rho-n}=\frac{u^{\prime \prime}}{\rho-n} \dot{k} .
$$

Denote by $c_{l}^{A}\left(c_{l}^{B}\right)$ the initial consumption chosen on path $A(B)$. Then the value of the program is $H\left(k_{l}, c_{l}^{A}\right)\left(H\left(k_{l}, c_{l}^{B}\right)\right)$, respectively. Consider the case $k(0)=k_{l}$ [Fig. 5]. Because the point $\left(k_{l}, c_{l}^{B}\right)$ lies on the $\dot{k}=0$-line but $\left(k_{l}, c_{l}^{A}\right)$ above it (with $\left.\dot{k}<0\right)$, Eq. (18) implies $H\left(k_{l}, c_{l}^{A}\right)>H\left(k_{l}, c_{l}^{B}\right)$. Hence, for $k(0)=k_{l}$, path $A$ is optimal. By an analogous argument, for $k(0)=k_{h}$, path $B$ is optimal.

To consider $k(0) \in\left(k_{l}, k_{h}\right)$, note that an optimal path satisfies

$$
\frac{d c}{d k}=\frac{\dot{c}}{\dot{k}}=\frac{-\frac{u^{\prime}}{u^{\prime \prime}}\left\{\frac{-n^{\prime} H(k, c)}{u^{\prime}}-\left[f^{\prime}-(\delta+\rho)-n^{\prime} \cdot k\right]\right\}}{\dot{k}},
$$

and along an optimal path, $c=c(k)$. Then it holds

$$
\begin{aligned}
\frac{d H[k, c(k)]}{d k} & =\frac{\partial H[k, c(k)]}{\partial k}+\frac{\partial H[k, c(k)]}{\partial c} \frac{\dot{c}}{\dot{k}} E q . \\
& =\frac{n^{\prime}}{(\rho-n)^{2}}\left(u+u^{\prime} \dot{k}\right)+\frac{u^{\prime}}{\rho-n}\left[f^{\prime}-(\delta+n)-n^{\prime} \cdot k\right]-\frac{u^{\prime \prime} \dot{k}}{\rho-n} \frac{\dot{c}}{\dot{k}} \\
& =\frac{n^{\prime}}{\rho-n} H(k, c)+\frac{u^{\prime}}{\rho-n}\left[f^{\prime}-(\delta+n)-n^{\prime} \cdot k\right]-\frac{u^{\prime \prime} \dot{c}}{\rho-n} \\
& =u^{\prime}>0 .
\end{aligned}
$$

\footnotetext{
${ }^{18}$ The following discussion utilizes the properties of optimized Hamiltonian, as has been suggested by Tahvonen and Salo (1996).
} 
Consider some $k(0) \in\left(k_{l}, k_{h}\right)$ such that $A$ is optimal. Path $A$ can be reached by choosing one of several initial consumptions [Fig. 5] and assume that the lowest possible initial consumption is chosen. To reach $k_{1}^{*}$, it is first necessary to move along $A$ from $k(0)$ to $k_{h}$ and then from $k_{h}$ to $k(0)$ [Fig. 5]. According to Eq. (19), the former (latter) increases (decreases) the value of the program. Furthermore, because $u^{\prime \prime}<0$, the increase of $H[k, c(k)]$ as a function of $k$ is faster for lower values of $c(k)$, and the (net) value of the program increases in moving from $k(0)$ through $k_{h}$ back to $k(0)$. Hence, if $A$ is optimal, then the highest possible initial consumption is to be chosen. By an analogous argument, if $B$ is optimal, then the lowest possible consumption should be chosen. Hence, it never optimal to move along the spiral.

Consider an increase in $k(0)$; Eq. (19) implies that $H[k, c(k)]$ increases. Further, for all $k(0) \in\left(k_{l}, k_{h}\right)$ the optimal $c(0)$ is lower on $B$ than on $A$ [Fig. 5]. Hence, Eq. (19) implies that $H[k, c(k)]$ increases faster along $B$ than along $A$. Because $H[k, c(k)]$ is continuous in $k$, and because $H\left(k_{l}, c_{l}^{A}\right)>$ $H\left(k_{l}, c_{l}^{B}\right)$ but $H\left(k_{h}, c_{h}^{A}\right)<H\left(k_{h}, c_{h}^{B}\right)$, there exists $k_{m} \in\left(k_{l}, k_{h}\right)$ such that $H\left(k_{m}, c_{m}^{A}\right)=H\left(k_{m}, c_{m}^{B}\right)$, and this $k_{m}$ is unique. Hence, for $k(0)=k_{m}$ the planner is indifferent in terms of $A$ and $B$, but for $k(0)<k_{m}$, it is optimal to choose $A$, whereas for $k(0)>k_{m}$, path $B$ is optimal.

Consider the case depicted in Figure 4 . For $k(0) \leq k_{1}^{*}$, path $B$ lies below $A$ and both paths lie below $\dot{k}=0$ where $\dot{k}>0$. Hence, Eq. (18) implies $H\left(k, c^{B}\right)>H\left(k, c^{A}\right)$. For $k_{1}^{*}<k(0)<k_{h}$, path $B$ lies below $A$. Hence, Eq. (19) implies that the value of the program increases faster along $B$ as $k(0)$ increases. Therefore, path $B$ is globally optimal. 


\section{References}

Azariadis, C. and Drazen, A. (1990). Threshold externalities in economic development. Quarterly Journal of Economics 105: 501-526.

Bar, M. and Leukhina, O. (2010). Demographic transition and industria revolution: A macroeconomic investication. Review of Economic Dynamics 13: $424-451$.

Barro, R. and Sala-i-Martin, X. (1995). Economic growth (1st edition). New York: McGraw-Hill.

Becker, G. (1960). An economic analysis of fertility. In Demographic and economic change in developed countries : a conference of the UniversitiesNational Bureau Committee for Economic Research. Princeton: Princeton University Press, 209-231.

Benhabib, J. and Farmer, R. (1994). Indeterminacy and increasing returns. Journal of Economic Theory 63: 19-41.

Benhabib, J. and Gali, J. (1995). On growth and indeterminacy: some theory and evidence. Carnegie-Rochester Conference Series on Public Policy 43: 163-211.

Bergstrom, T. (2007). Some evolutionary economics of family partnerships. American Economic Review 97: 482-486.

Bloom, D. and Williamson, J. (1998). Demographic transitions and economic miracles in emerging Asia. The World Bank Economic Review 12: 419-455. Bonneuil, N. (2010). Family regulation as a moving target in the demographic transition. Mathematical Social Sciences 59: 239-248. 
Caldwell, J. ( 1982). Theory of fertility decline. London: Academic Press.

Caselli, F. (2004). Accounting for cross-country income differences. CEPR Discussion Paper 4703.

Cervellati, M. and Sunde U. (2005): Human Capital, Life Expectancy and the Process of Development. American Economic Review 95(5): 1653-1672. de la Croix, D. and Doepke, M. (2003). Inequality and growth: Why differential fertility matters. American Economic Review 93: 1091-1113.

de la Croix, D. and Doepke, M. (2004). Public versus private education when differential fertility matters. Journal of Development Economics 73: $607-639$.

Doepke, M. (2004). Accounting for fertility decline during the transition to growth. Journal of Economic Growth 9: 348-383.

Gali, J. (1996). Multiple equilibria in a growth model with monopolistic competition. Economic Theory 8: 251-266.

Galor, O. and Weil, D. (1996). Gender gap, fertility, and growth. American Economic Review 86: 374-387.

Galor, O. and Weil, D. (2000). Population, technology, and growth: from Malthusian stagnation to the demographic transition and beyond. American Economic Review 90: 806-826.

Graham, B. and Temple, J. (2006). Rich nations and poor nations: how much can multiple equilibria explain? Journal of Economic Growth 11: 5-41.

Hall, R. (1988). Intertemporal substitution in consumption. Journal of Political Economy 96: 339-357. 
Hall, R. and Jones, C. (1999). Why do some countries produce so much more output per worker than others? Quarterly Journal of Economics 114: 83-116.

Hansen, G. and Prescott, E. (2002): Malthus to Solow. American Economic Review 92: 1205-1217.

Hazan, M. and Berdugo, B. (2002). Child labor, fertility, and economic growth. The Economic Journal 112: 810-828.

Heston, A., Summers, R. and Aten, B. (2009). Penn World Table Version 6.3. Center for International Comparison of Production, Income and Prices at the University of Pennsylvania.

Jones, L. and Schoonbrodt, A. (2010). Complements versus substitutes and trends in fertility choice in dynastic models. International Economic Review 51: 671-699.

Kremer, M. and Chen, D. (2002). Income distribution dynamics with endogenous fertility. Journal of Economic Growth 7: 227-258.

Lagerlöf, N.-P. (2003). Gender equality and long-run growth. Journal of Economic Growth 8: 403-426.

Lagerlöf, N.-P. (2006). The Galor-Weil model revisited: A quantitative exercise. Review of Economic Dynamics 9: 116-142.

Lane, J. (1975). A synthesis of the Ramsey-Meade problems when population change is endogenous. Review of Economic Studies 42: 57-66.

Lehmijoki, U. (2004). Demographic transition in the Ramsey model: do country-specific features matter? HECER Discussion Paper 32. 
Livi-Bacci, M. ( 1997). A concise history of world population. Oxford (UK): Blackwell Publishers.

Matsuyama, K. (1991). Increasing returns, industrialization, and indeterminacy of equilibrium. Quarterly Journal of Economics 105: 617-650.

Prescott, E. (1998). Needed: A theory of total factor productivity. International Economic Review 39: 525-551.

Solow, R. (1956). A contribution to the theory of economic growth. Quarterly Journal of Economics 70: 65-94.

Skiba, A. (1978). Optimal growth with convex-concave production function. Econometrica 46: 527-539.

Tahvonen, O. and Salo, S. (1996). Nonconvexities in optimal pollution accumulation. Journal of Environmental Economics and Management 31: 160177.

Uzawa, H. (1968). Time preferences, the consumption function, and optimum asset holdings. In Wolfe, J. (Ed.), Value, capital, and growth. Chicago: Aldine.

US Census Bureau (2010). IDB database, on-line version. 